\title{
Homework's in Primary School: The Case of the Curricular Area of "Environment Study"
}

\author{
António Costa, José Miguel Salgado, Maria Eduarda Ferreira* \\ Research Unit for Inland Development, Polytechnic Institute of Guarda, Portugal
}

Copyright $\bigcirc 2018$ by authors, all rights reserved. Authors agree that this article remains permanently open access under the terms of the Creative Commons Attribution License 4.0 International License

\begin{abstract}
This research seeks to develop a critical reflection that frames, characterizes and evaluates the homework as a teaching strategy in the curricular area of "Environment Study" in the Portuguese primary education. For that, we considered three dimensions: the type of methodology used; the number of homework assignments; the duration of the assignment by the student according to the time provided by the teacher. For methodologic purposes, we followed the case study method as we wanted to investigate the homework during a definite period in a narrative and profound way. An original instrument, called Homework Data Collection, was created to answer the three research questions. The results show that there isn't a preferred homework methodology. We found also a lack of proportionality between work time and study hours of "Environmental Study". About the time taken by students to perform homework, we found that teachers are very well prepared to predict the time students take.
\end{abstract}

Keywords Homework, Primary School, Environment Study

\section{Introduction}

Education is seen in every age in a very different way, fulfilling the aspirations that shape each generation. As such, Education is an organic process, which, cyclically, is recycled / renewed by the concern to maintain quality standards and by the intellectual goals of education, without ever abandoning the premise on which education serves as a means to prepare balanced citizens for democracy [1].

Seeing the educational process as a very great influence in society should be the subject of deep reflection. This reflexive spirit must not fail to scrutinize everyone in the process, trying to answer questions such as: What should we teach? What should be the ends? And what strategies need to be developed? Where does the school constitute the center of the school and the family and the teachers as conditioning agents/facilitators of the educational process?

The Portuguese educational system is ruled by the Basic Law ( $n^{\circ} 46 / 86$ of October 14. Art. 7: 3069) and legitimizes the compulsory and free universal character of basic education, in which primary education is integrated.

Reference [2, p.11] shows that "(...) basic education is the stage of schooling in which the democratic principle that informs the entire educational system is made more widely, and in turn contributes decisively to deepening the democratization of society in a perspective Development and progress, by promoting the individual realization of all citizens, in harmony with the values of social solidarity, and by preparing them for a useful and responsible intervention in the community".

This level of schooling comprises four years of schooling, with an age range from 6 to 9 years old, providing a global teaching responsibility of a single teacher, with competencies being developed in the following curricular areas: Mother Tongue ("Portuguese"), "Mathematics", "Environment Study" and "Artistic/Physical-motor Expressions". Primary education is governed by a formal curriculum of its own and each area has a curriculum as well as targets to be met. It should be noted that the curricular plan of this basic cycle also supports the integration of experimental and research activities in the work to be developed by the students, appropriate to the nature of the different areas, namely in science teaching. But, the School is also an institution for the promotion of social values, never ceasing to be inclusive, and is seen as an instrument used by the citizen for social ascension.

It is in this context that the School should develop a set of educational strategies inside and outside the classroom. One of those that has divided the school and scientific community is the achievement or not, by the students, of works outside the context of the classroom, commonly known as "homework" (HW). This terminology is widely known by some authors as the most timeless teaching strategy used throughout the world. 
The literature defines HW as the academic work prescribed by the teacher in the school, and which must be completed by the students outside the school, over time, usually at home and, therefore, without the direct guidance of the teacher during their performance [3, 4]. This concept is further exaggerated by excluding school-based study, home-based correspondence courses on television, audio or video, or on the internet, and extracurricular activities such as group sports and clubs [4]. Already for Corno [5], HW is not limited to classrooms, where the teacher and the student occupy the main role, extending to third parties (parents, explainers and other members involved in the educational process) and whose role may be essential for the final quality of the work done.

Marzano and Pickering [6] state that teachers should not abandon HW. Instead, they argue that their instructional quality should be improved, challenging a reflection on the role of HW as a strategy for student success. As part of a range of strategies that have been maintained over time, along with the expository method, homework was seen for many years in our educational system as an important pedagogical resource for the consolidation of knowledgeDespite that, in recent years, a part of the scientific community has been looking critically at these tasks, not recognizing them pedagogical value. This line of thought is creating a sharp division between researchers who recognize the value of homework and those who view these tasks as a hindrance, resulting in relatively dense scientific output with well-defined positions.

Being a controversial subject in the universe of Education, the HW is well studied, with a vast literature that gave rise to more traditional models and, more recently, to other models of the self-regulatory matrix. In the more traditional HW models the focus is directed to the analysis of the degree of involvement of students with homework, varying according to the support provided by the teacher(s) and the parents or caregivers [7]. In this universe of models, one of the first to emerge was Cooper's procedural model [4]. The Cooper model defines as exogenous factors that can influence the effect of the HW on the individual characteristics of the students, with emphasis on competence, motivation and study habits, curricular discipline with respect to HW, student's year of schooling, as well as individual differences, which include, for example, gender and socio-economic conditions. As for endogenous factors, the model presents them by dividing them between the characteristics of the task and the home-community phase, where potential influences are defined by the effects of HW. Finally, the model presents the possible consequences of the HW process in terms of its final results [4]. The originality of the Cooper model from the previous ones is in the introduction of the characteristics of the HW tasks as potential mediators of this process. It considers that the following should be taken into account: load, objective, the area of competence used (e.g. reading, writing), the degree of individualization, the degree of student choice, completion period and social context. It should also be pointed out that in this model the emphasis is placed on parental factors associated with $\mathrm{HW}$, in detriment of self-regulating factors regarding students. This selection puts aside the specific processes used by the students during the realization of the HW, where they are inserted, goal setting, planning, self-monitoring, self-assessment, self-instruction or self-reaction, characteristic of a more specificity of the task.

This research is focused on the curriculum area of the Study of the Environment. According to Roldão [8] this area seeks the understanding of the world. It seeks to bring the child closer to the natural-environmental, physical and social reality.

Children of this age level perceive reality as a globalized whole. For this reason, "Environment Study" is presented as an area for which concepts and methods from various scientific disciplines such as History, Geography, Nature Sciences, Ethnography, and others compete, thus contributing to the progressive understanding of the interrelationships between Nature and Society [2].

\section{Method}

The present study was developed in a school in the interior region of Portugal, a region demographically ranked of low density. According to PORDATA data [9], in 2016, 6744 students were enrolled in the schools of the county, of which 1441 attended the first cycle of primary education. The school where the study was conducted is a private school with different levels of education from kindergarten up to secondary. We only focus our attention on the first cycle where can find eight class $(1 \mathrm{~A}, 1 \mathrm{~B}, 2 \mathrm{~A}$, 2B, 3A, 3B, 4A, and 4B) with eight teachers and 163 children.

Before any data collection carried out, the project was presented to the pedagogical board of the institution, which at a meeting of the school Pedagogical Council, approved the realization of the study with the recommendation to keep the data collected confidentially. On the other hand, the same Pedagogical Council recommended a limit of 2 homework assignments per student per week.

After the permission, and throughout 2016/2017 school year, we collected data about HW in all eight classes with teachers help. To compile those data we used the instrument named Data collection about homework. But, before presenting and exploring the methodological tool, we must go through the research questions.

According to the existing literature and some exploratory studies developed previously $[4,10,11]$, this work seeks to answer the following questions:

Research question 1: Which is the homework's 
methodology preferred by teachers?

Research question 2: The number of Environment Study's homework per week is proportional to the number of hours per week of this subject?

Research question 3: Is the time predicted by the teachers in the accomplishment of the homework similar to the time needed by the children in the accomplishment of that homework?

\subsection{Instrument}

The tool previously called Data collection about homework was initially produced for this study. This instrument was validated by conducting a pilot test with the collaboration of first cycle school teachers' where the study was conducted. After the corrections, the tool was delivered to the eight teachers who began collecting data on HW in the subject of Environmental Study.

This instrument seeks to analyze the teacher and children's perspective on Homework. For these purposes it was collected, at the teacher level, the methodology used and the time provided for the accomplishment of this task. In students' side, it was registered the accomplishment/not accomplishment of this task and the adequate time for its achievement.

Through this instrument, we have been able to collect information about different categories such as the typology, the expected time for the realization, the actual time of the achievement, the place where it is executed and of who accompanies in the execution of the HW. For each category, we create subcategories related to the class. For example, the place where it is executed has three different subcategories: school (support to study), home and Study Center locals outside of school where children have the support to study). In category who accompanies in the execution, we create four different subcategories: school teacher (support to study), parents, brothers or others. For the typology category, we create four subcategories: worksheet, exercise-solving; problem-solving and others.

\subsection{Research Sample}

Teacher's characterization: eight teachers participated in this study: $87.5 \%$ are females and $12.5 \%$ are males with an average age of 36.6 years old. Also; it is a group of relatively young teachers with an average of 10.5 years of teaching experience, almost all the time - average 9.8 years - in primary school level.

Student's characterization: 163 children between six and ten years old - 55\% are male, and $45 \%$ female - of a primary school. The children are spread over eight classes, two for each one of the four levels. So, each class presents an average of 20,3 children.

\section{Findings}

Throughout 2016/2017 school year, we have 25 complete weeks of data available in all the subjects. This data gives us an average of 2,7 HW assignments per week, above the recommendation of the school Pedagogical Council, but only $22 \%$ of that value corresponds to HW related to "Environment Study". The associated variance is minimal, typically a standard deviation distance away. We also registered the weekdays of "Environment Study" HW assignments (Table 1).

Clearly, the assignment days have something to do with the school structure and orientation about homework. For most of the teachers, the three days where we can find homework assignment are the three days that the school offers extra after-school support from the teacher.

Table 1. Weekday versus number of assignments

\begin{tabular}{|c|c|c|c|c|c|c|c|c|c|}
\hline Weekday & 1A & 1B & 2A & 2B & 3A & 3B & 4A & 4B & Assignments (\%) \\
\hline Monday & 0 & 2 & 4 & 1 & 6 & 6 & 0 & 3 & 22 \\
\hline Tuesday & 6 & 0 & 3 & 3 & 2 & 0 & 5 & 0 & 19 \\
\hline Wednesday & 0 & 0 & 0 & 0 & 4 & 5 & 5 & 3 & 17 \\
\hline Thursday & 2 & 1 & 3 & 10 & 4 & 0 & 8 & 0 & 28 \\
\hline Friday & 3 & 2 & 0 & 0 & 7 & 8 & 5 & 0 & 25 \\
\hline
\end{tabular}




\section{Environmental Study's HW Average per week per class}

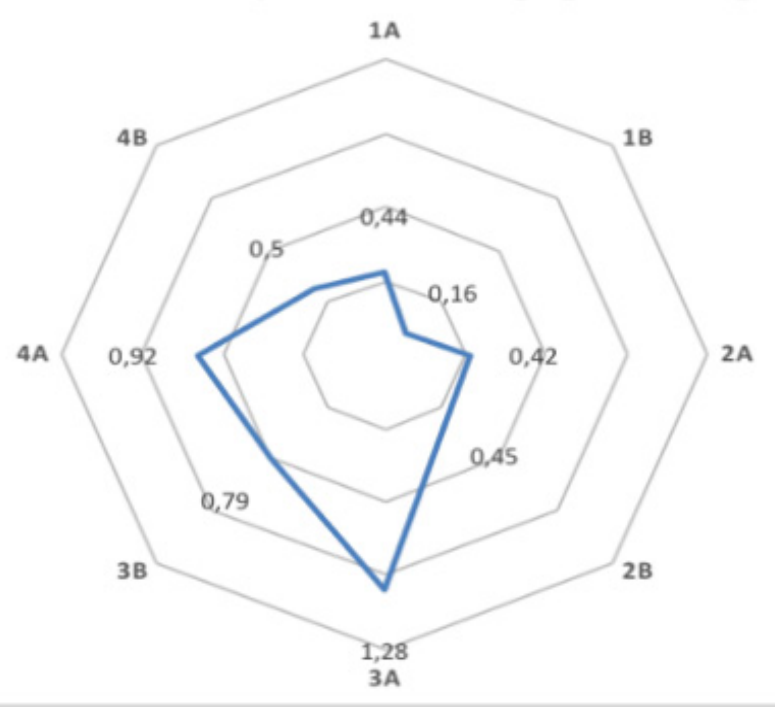

Figure 1. Environmental Study's HW Average per Week per class

Focusing our attention on the number of HW per week per class, we conclude that the weekly average is 0.62 , with a higher incidence of $3 \mathrm{~A}$ and lower incidence on $1 \mathrm{~B}$ (figure 1).

Comparing the relative weight of the HW of the "Environmental Study" with the other disciplines, it can be verified that as student progress in the cycle, the relative importance of "Environmental Study" increases up to 30\% (Figure 2).

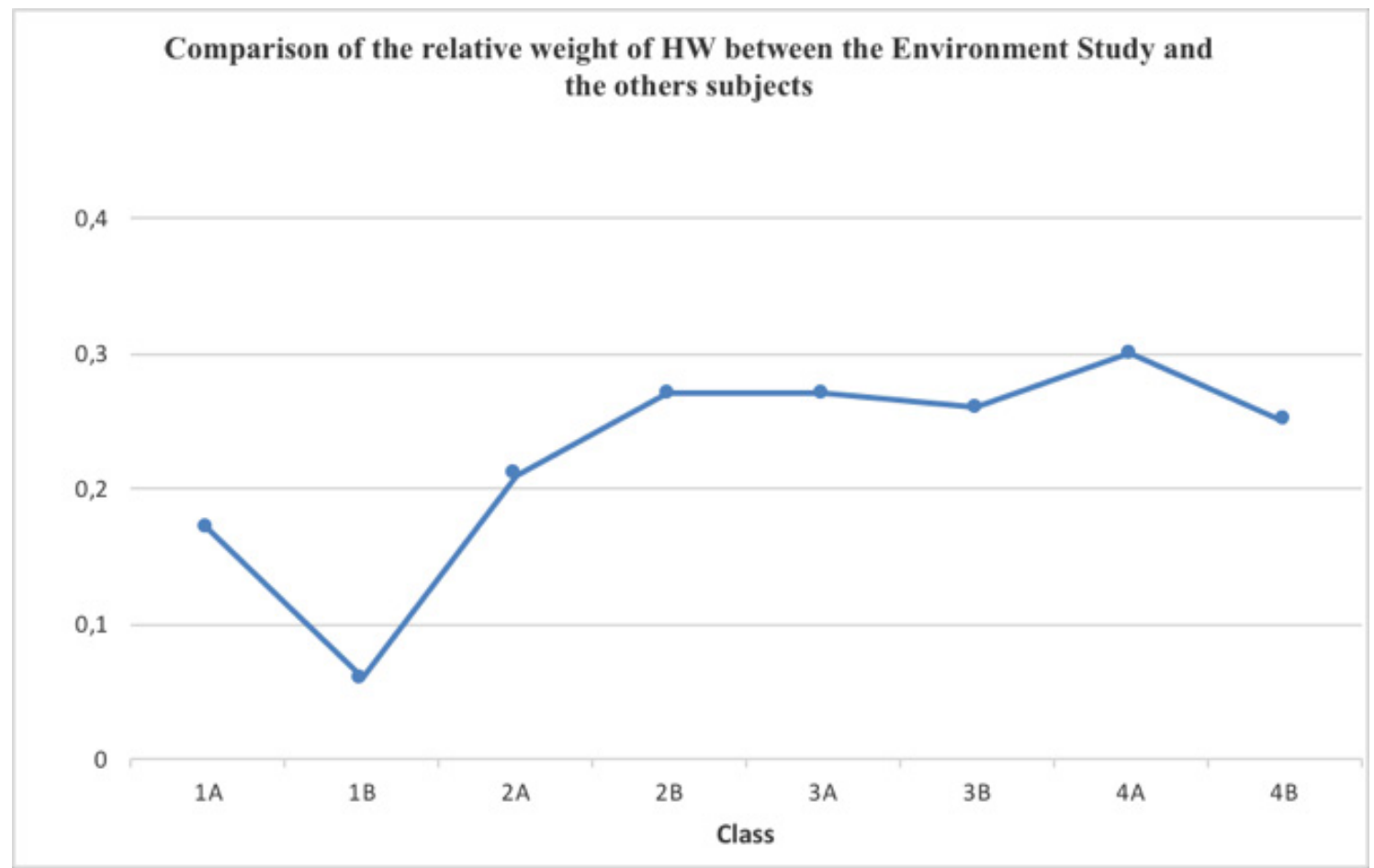

Figure 2. Comparison of the relative weight of HW between the "Environment Study" and the other subjects

About the distribution of the typology of HW in Environmental Study, we got $65 \%$ for others, $31 \%$ for the worksheet, $4 \%$ for exercise-solving and $0 \%$ for problem-solving (Figure 3). 


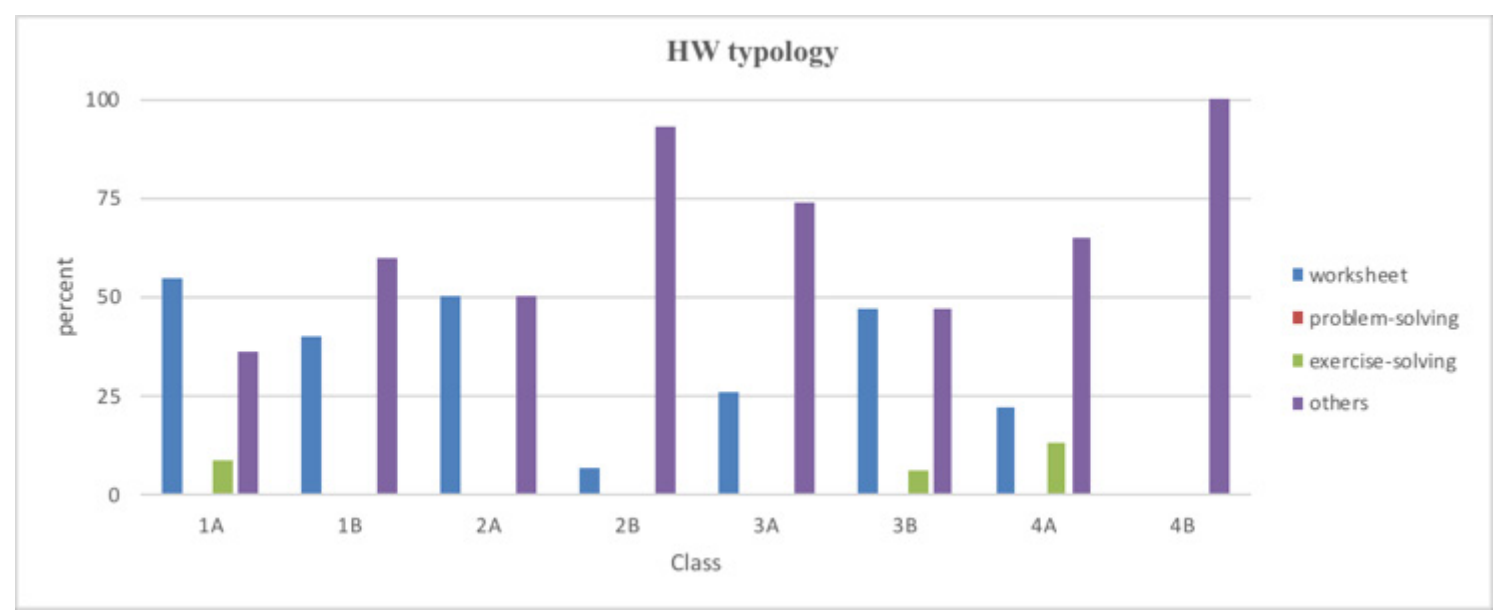

Figure 3. HW typology

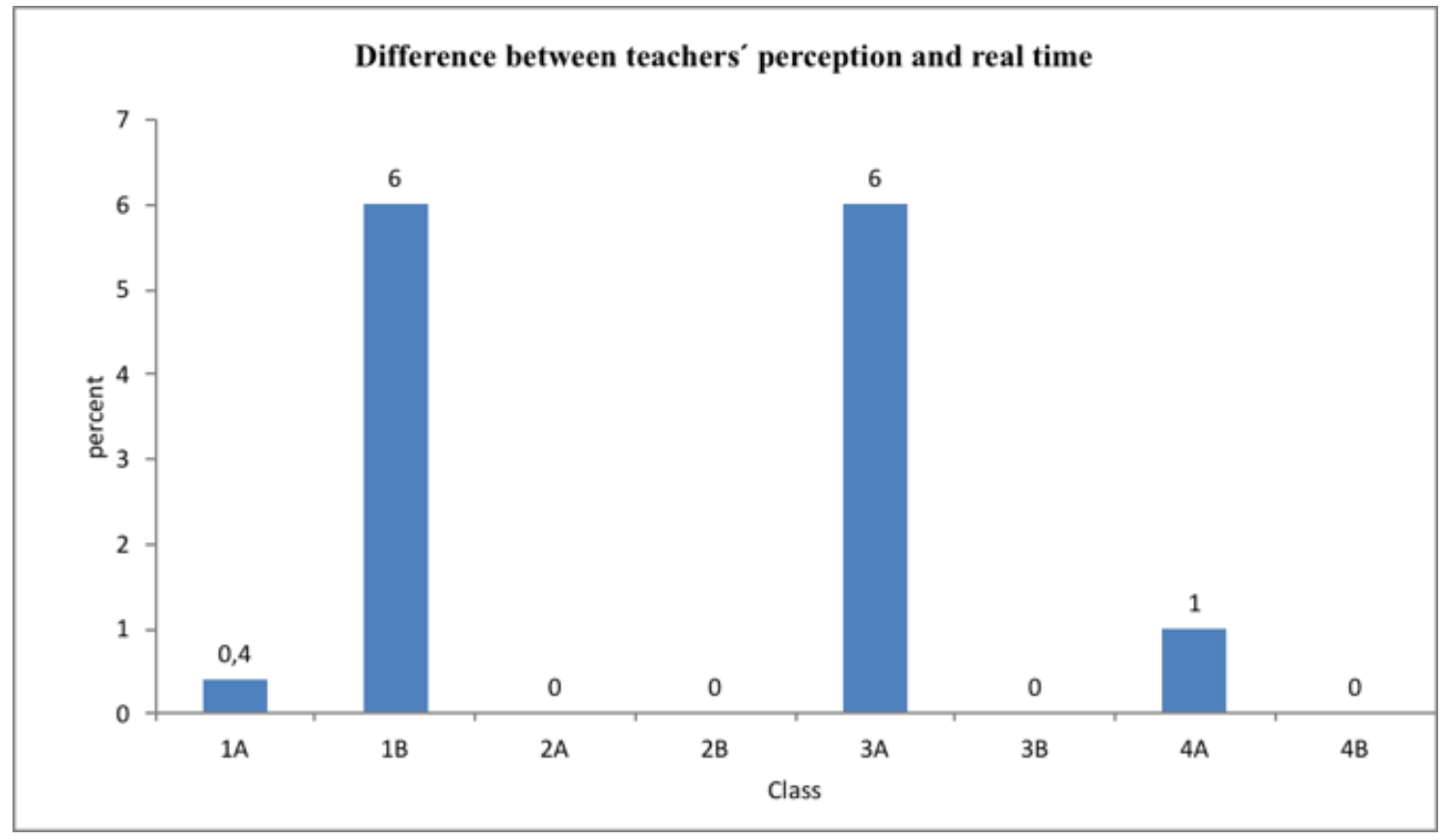

Figure 4. Difference between teachers perception and real-time

Given the data obtained, there is no fixed typology of homework. We can verify that the others typology is the most important almost in every year. In this subcategory are inserted several types of activities, without the prevalence of any of them.

It is important to highlight the lack of use of problem-solving, which may indicate difficulties in the implementation of this methodology in the classroom, which is reflected in the subsequent transfer to HW activities.

It is also worth highlighting the reasonably regular use of worksheets, which may suggest that repetition/memorization is still a strategy rooted in the classroom.

The total time for all classes to carry out the homework was 964,26 minutes, that means 14,61 minutes/week/class. So, considering an average class teaching time of 3,5 hours, homework takes around $7 \%$ of class time.

Only in $6 \%$ of the HW assignments, we found differences between the teacher's perception and the real time that takes to accomplish the task by the children. In this $6 \%$, most of the perception errors are less than 5 minutes per defect, that is, teachers tend to consider that it takes less time to perform the task than what happens. We can, then, estimate a global perception mislead of $2 \%$ (Figure 4).

\section{Conclusions}

"Environmental Study" is an essential subject in Primary School, but according to the results only in the later years of Primary School, the HW is used as a methodology to improve the students' scientific knowledge. At the 
beginning of the first cycle, teachers use $\mathrm{HW}$ as a methodology more in "Mother Languages" and "Math" than in "Environmental Study."

When HW is used as a methodology, it's not possible to gauge HW's type preferred by teachers. Regularly they selected between others and worksheet types.

On the other hand, about the proportionality between HW time and the number of teaching hours in Environmental Studies, we can say that, in average, there is the proportionality of $7 \%$, but there are so many differences between the classes. Just as an example, one of the classes did not have any homework in a four week period, while other class reached a maximum of nine homework assignments in the same period.

About the teacher's perception of the time necessary to accomplish the homework on Environmental Study, we can conclude that most of the times teachers have a very good understanding of the time needed to perform the homework. So, the current erroneous perception is minimal.

According to the results, we can conclude that the HW's methodology isn't preferred by teachers in the early years of the first cycle in "Environmental Study." This idea reflected a lack of proportionality between working time and study hours of Environmental Study, even if there isn't a so marked discrepancy between the time determined by the teacher in the performance of the homework and the adequate time that the student took to perform the tasks.

As a future goal, we also intend to extend this research in a public school setting.

\section{Acknowledgments}

This work was financed by Research Unit for Inland Development, Polytechnic Institute of Guarda.

A special thanks to the school for the full readiness to participate in this research work.

\section{REFERENCES}

[1] J. Brunner, The process of education. Harvard University Press, London, 1977.

[2] M. Educação, Organização Curricular e Programas: Ensino Básico - $1^{\circ}$ Ciclo, Direção do Ensino Básico, Lisboa, 2004.

[3] P. Rosário, R. Mourão, S. Soares, E. Chaleta, L. Grácio, F. Simões, J. Nunez, J. Gonzalez-Pienda, Trabalho de casa, tarefas escolares, auto-regulação e envolvimento parental, Psicologia em Estudo, Vol.10, No. 3, 343-351, 2005.

[4] H. Cooper, The battle over homework: Common ground for administrators, teachers, and parents, Corwin Press, Thousand Oaks, 2006.

[5] L. Corno, Volitional Aspects of Self-Regulated Learning. In B. J. Zimmerman \& D. H. Schunk (Eds.), Self-regulated learning and academic achievement: Theoretical Perspectives, Lawrence Erlbaum Associates, New Jersey, 2001.

[6] R. Marzano, J. Pickering, The case for and against homework, Educational Leadership, Vol. 64, No. 6, 74-79, 2007.

[7] H. Bembenutty, Predicting homework completion and academic achievement: The role of motivational beliefs and self-regulatory processes, ProQuest Dissertations Publishing, City University of New York, 2005

[8] M. Roldão, Estudo do Meio no $1^{\circ}$ Ciclo - Fundamentos e estratégias, Texto Editores, Lisboa, 2004.

[9] Online Available: https://www.pordata.pt/Municipios

[10] J. Xu, Purposes for doing homework reported by middle and high school students, Journal of Educational Research, Vol. 99, No. 1, 46-55, 2005.

[11] J. Xu, R. Yuan, Doing homework: Listening to students', parents', and teachers' voices in one urban middle school community, School Community Journal, Vol. 13, No. 2, 23-44, 2003. 